\title{
Study on Properties of Rice Husk Ash and Its Use as Cement Replacement Material
}

\author{
Ghassan Abood Habeeb*, Hilmi Bin Mahmud \\ Department of Civil Engineering, Faculty of Engineering, \\ University of Malaya, Kuala Lumpur, Malaysia
}

Received: November 7, 2009; Revised: March 21, 2010

\begin{abstract}
This paper investigates the properties of rice husk ash (RHA) produced by using a ferro-cement furnace. The effect of grinding on the particle size and the surface area was first investigated, then the XRD analysis was conducted to verify the presence of amorphous silica in the ash. Furthermore, the effect of RHA average particle size and percentage on concrete workability, fresh density, superplasticizer (SP) content and the compressive strength were also investigated. Although grinding RHA would reduce its average particle size (APS), it was not the main factor controlling the surface area and it is thus resulted from RHA's multilayered, angular and microporous surface. Incorporation of RHA in concrete increased water demand. RHA concrete gave excellent improvement in strength for $10 \%$ replacement (30.8\% increment compared to the control mix), and up to $20 \%$ of cement could be valuably replaced with RHA without adversely affecting the strength. Increasing RHA fineness enhanced the strength of blended concrete compared to coarser RHA and control OPC mixtures.
\end{abstract}

Keywords: fineness, pozzolan, compressive strength, XRD

\section{Introduction}

Rice husk is an agricultural residue which accounts for $20 \%$ of the 649.7 million tons of rice produced annually worldwide ${ }^{1}$. The produced partially burnt husk from the milling plants when used as a fuel also contributes to pollution and efforts are being made to overcome this environmental issue by utilizing this material as a supplementary cementing material ${ }^{2}$. The chemical composition of rice husk is found to vary from one sample to another due to the differences in the type of paddy, crop year, climate and geographical conditions ${ }^{3}$.

Burning the husk under controlled temperature below $800^{\circ} \mathrm{C}$ can produce ash with silica mainly in amorphous form ${ }^{3-5}$. Recently, Nair et al. ${ }^{6}$ reported an investigation on the pozzolanic activity of RHA by using various techniques in order to verify the effect of incineration temperature and burning duration. He stated that the samples burnt at 500 or $700{ }^{\circ} \mathrm{C}$ and burned for more than 12 hours produced ashes with high reactivity with no significant amount of crystalline material. The short burning durations (15 - 360 minutes) resulted in high carbon content for the produced RHA even with high incinerating temperatures of 500 to $700{ }^{\circ} \mathrm{C}$. A state-of-the-art report on rice husk ash (RHA) was published by $\mathrm{Mehta}^{7}$ in 1992, and contains a review of physical and chemical properties of RHA, the effect of incineration conditions on the pozzolanic characteristics of the ash, and a summary of the research findings from several countries on the use of RHA as a supplementary cementing pozzolanic material.

According to the author's literature, RHA has not been utilized in the construction industry yet, the reason for that may be due to the lack of understanding of the RHA blended concrete characteristics.

\section{Scope of Work}

The work presented in this paper reports an investigation on the behaviour of concrete produced from blending ASTM Type I cement with RHA having various APS. The physical and chemical properties of RHA were first investigated and compared to the ordinary Portland ${ }^{\circledR}$ cement (OPC). Mixture proportioning was performed to produce high workability concrete ( $200-240 \mathrm{~mm}$ slump) with target strength of $40 \mathrm{MPa}$ for the control mixture. A total of 13 concrete mixtures were casted to study the effect of RHA average particle size (APS) and the level of replacement on the properties of fresh concrete and compressive strength.

\section{Experimental Work}

\subsection{Materials}

\subsubsection{Cement}

Ordinary Portland ${ }^{\circledR}$ Cement (OPC) conforming to ASTM C 150 type I was used for this study, its chemical and physical properties are given in Table 1. The cement was tested for its mineral content and the loss on ignition using the X-ray Fluorescence (XRF) analysis. The average particle size distribution was determined by laser particle analysis using the MasterSizer Laser Particle Analyser with obscuration 12.3\% and beam length of $2.40 \mathrm{~mm}$. The specific gravity (SG) of cement was determined according to the British Standard (BS 1377: Part 2) using the small pycnometer method. The fineness of the cement was determined by conducting the Blaine surface area test according to ASTM C 204-94a and shown in Table 2.

\subsubsection{Aggregate}

The fine aggregate used was mining sand passing by $4.75 \mathrm{~mm}$ sieve. The coarse aggregate was crushed granite with size of $4.75-19 \mathrm{~mm}$. The specific gravity as well as absorption tests for both coarse and fine aggregate were done as specified in ASTM C 127-88 and ASTM C128-97, respectively. The sieve analysis 
was done in compliance with BS 882:1992. The properties of the aggregates are shown in Table 3.

\subsubsection{Chemical admixture}

In order to maintain the high workability of the concrete mixtures, an ASTM C494 type-A high range water-reducing admixture R1000 superplasticizer was used, which is a dark brown, water-soluble, chloride free sulphonated naphthalene formaldehyde. According to the manufacturer, it has $40 \%$ solid content with specific gravity of 1.2.

\subsubsection{Rice husk ash}

The husk was collected from paddy field in Kuala Selangor, Malaysia, it was then burned in the laboratory by using a ferro-cement

Table 1. Chemical and physical properties of OPC and RHA.

\begin{tabular}{crr}
\hline Oxide composition $(\%$ by mass $)$ & OPC & RHA \\
\hline $\mathrm{SiO}_{2}$ & 20.99 & 88.32 \\
$\mathrm{Al}_{2} \mathrm{O}_{3}$ & 6.19 & 0.46 \\
$\mathrm{Fe}_{2} \mathrm{O}_{3}$ & 3.86 & 0.67 \\
$\mathrm{CaO}$ & 65.96 & 0.67 \\
$\mathrm{MgO}$ & 0.22 & 0.44 \\
$\mathrm{Na}_{2} \mathrm{O}_{3}$ & 0.17 & 0.12 \\
$\mathrm{~K}_{2} \mathrm{O}$ & 0.60 & 2.91 \\
$\mathrm{LOI}$ & 1.73 & 5.81 \\
Specific gravity & 2.94 & 2.11 \\
\hline
\end{tabular}

Table 2. The average particle size and surface area of OPC and RHA with different APS.

\begin{tabular}{cccccc}
\hline Material & OPC & RHAF0 & RHAF1 & RHAF2 & RHAF3 \\
\hline $\begin{array}{c}\text { Grinding time } \\
\text { (minutes) }\end{array}$ & - & 90 & 180 & 270 & 360 \\
$\begin{array}{c}\text { Average particle size } \\
(\mu \mathrm{m})\end{array}$ & 22.1 & 63.8 & 31.3 & 18.3 & 11.5 \\
$\begin{array}{c}\text { BET nitrogen } \\
\text { adsorption }\left(\mathrm{m}^{2} . \mathrm{g}^{-1}\right) \\
\begin{array}{c}\text { Blaine's surface } \\
\text { area }\left(\mathrm{m}^{2} \cdot \mathrm{kg}^{-1}\right)\end{array}\end{array}$ & -351.4 & - & - & - & 30.4 \\
\hline
\end{tabular}

Table 3. Aggregates properties.

\begin{tabular}{ccccc}
\hline Properties & \multicolumn{2}{c}{ Fine aggregate } & \multicolumn{2}{c}{ Coarse aggregate } \\
\hline App. specific gravity & \multicolumn{2}{c}{2.61} & \multicolumn{2}{c}{2.65} \\
Water absorption $(\%)$ & \multicolumn{2}{c}{0.76} & \multicolumn{2}{c}{0.50} \\
\cline { 2 - 5 } & $\begin{array}{c}\text { Sieve size } \\
(\mathrm{mm})\end{array}$ & $\begin{array}{c}\text { Cumulative } \\
\text { retained }(\%)\end{array}$ & $\begin{array}{c}\text { Sieve size } \\
(\mathrm{mm})\end{array}$ & $\begin{array}{c}\text { Cumulative } \\
\text { retained (\%) }\end{array}$ \\
\cline { 2 - 5 }- & 4.750 & 0.00 & 19.00 & 0.00 \\
- & 2.360 & 16.91 & 13.20 & 43.80 \\
- & 1.180 & 35.31 & 9.50 & 68.69 \\
- & 0.600 & 58.12 & 4.75 & 100.00 \\
- & 0.300 & 81.39 & - & - \\
- & 0.150 & 93.10 & - & - \\
- & 0.075 & 97.18 & - & - \\
\hline
\end{tabular}

furnace ${ }^{8}$. This furnace (Figure 1) can hold up to $60 \mathrm{~kg}$ of rice husks; it has three small openings through which fire is ignited They too allow ventilation. A fire source was maintained under the furnace for around 10 minutes, after which the husks slowly burned for more than one day. The ash was left inside the furnace to cool down before it was collected.

The ash was ground for 90, 180, 270 and 360 minutes (Figure 2). The RHA ground for 90 minutes (RHAF0) was only tested for particle size analysis and surface area to show the effect of grinding time on the average particle size and specific surface area. Los Angeles (LA) mill was used to grind the ash; this machine consists of a rotating drum with an opening on top of it; inside the drum there are 40 mild steel rods (10 $\mathrm{mm}$ diameter and $500 \mathrm{~mm}$ length) for grinding the ash. The mill can hold up to $5 \mathrm{~kg}$ of ash and this amount was kept constant each time the mill was used. The milling time was adjustable in the range of ( 90 - 360 minutes) according to the required fineness. The $\mathrm{X}$-ray Diffraction (XRD) analysis was performed to determine the silica phase of the produced RHA powder samples, they were scanned by an X-ray diffractometer using $\mathrm{CuK} \alpha$ radiation at $40 \mathrm{kV} / 20 \mathrm{~mA}$, CPS $=1 \mathrm{k}$, width 2.5 , speed $2 \%$ min and scanning with angle of $2 \theta$ from $3-70^{\circ}$. To study the effect of grinding time on the average particle size (APS), the particle size analyses were carried out by using the MasterSizer laser particle analyser with obscuration $12.3 \%$ and beam length of $2.40 \mathrm{~mm}$. RHA samples were also scanned by

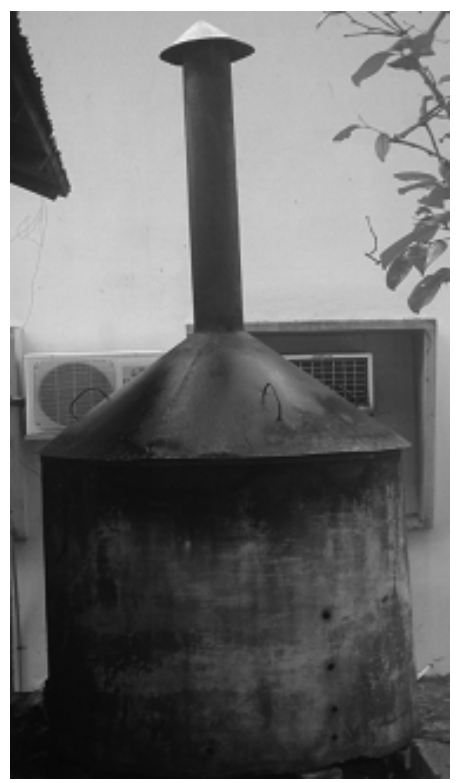

Figure 1. The ferro-cement furnace.

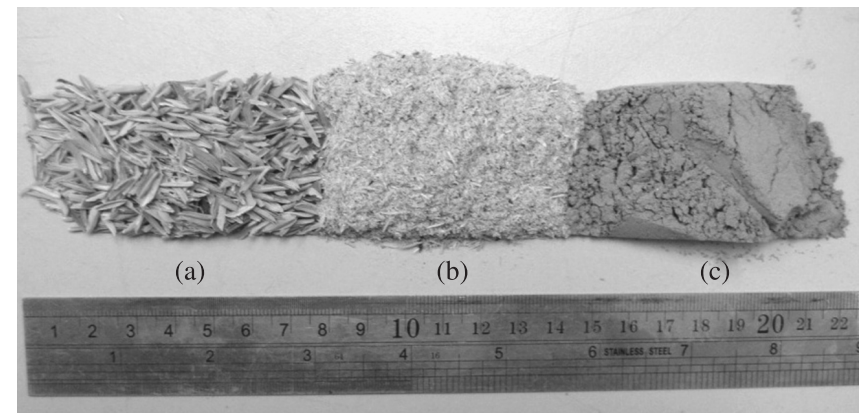

Figure 2. a) Rice husk, b) Burnt RHA and c) RHA after grinding. 
Table 4. Concrete mixture proportioning.

\begin{tabular}{|c|c|c|c|c|c|c|}
\hline Mix & Cement $(\mathrm{kg})$ & RHA F1/ F2/ F3 (kg) & Water (L) & Fine Agg. (kg) & Coarse Agg. (kg) & W/Binder \\
\hline $\mathrm{CM}$ & 391 & 0 & 207 & 750 & 994 & 0.53 \\
\hline 05RHA & 371 & 20 & 207 & 750 & 994 & 0.53 \\
\hline 10RHA & 352 & 39 & 207 & 750 & 994 & 0.53 \\
\hline 15RHA & 332 & 59 & 207 & 750 & 994 & 0.53 \\
\hline 20RHA & 313 & 78 & 207 & 750 & 994 & 0.53 \\
\hline
\end{tabular}

electron microscope to show the RHA's particles texture. The nitrogen adsorption test was done to verify the effect of grinding on the specific surface area of RHA. The chemical composition of the RHA is determined using the X-ray fluorescence spectrometry (XRF).

\subsection{The concrete mixture proportioning}

Mixture proportioning was carried out according to the current British mix design method (Department of Environment DOE) ${ }^{9}$. The target mean strength was $40 \mathrm{MPa}$ for the OPC control mixture, the total binder content was $391 \mathrm{~kg} . \mathrm{m}^{-3}$, fine to coarse aggregate ratio of $75.4 \%$, the water to binder ratio was kept constant as 0.53 , the superplasticizer content had to be adjusted to maintain a slump of $(200-240 \mathrm{~mm})$ for all mixtures. The total mixing time was 5 minutes then the samples were casted and left for 24 hours. After that, samples were demoulded and placed in the curing tank until the testing time at the age of 1, 3, 7, 28 days. Mixture proportions are summarized in Table 4.

In this study, the influence of RHA average particle size and the level of replacement were studied simultaneously, 5, 10, 15, and $20 \%$ of cement was replaced with three grades of RHA (F1, F2 and F3, i.e. 180, 270 and 360 minutes of grinding respectively). The properties of fresh concrete, i.e. slump and fresh density were studied, then, the compressive strength at the age of 1, 3, 7, 28 days was investigated. Specimens left in the casting room for 24 hours then moved into the water for curing until the time of testing. The slump test was conducted to evaluate workability and consistency of concrete. It was carried out in accordance to British Standard (BSI, BS 1881: Part 102). The fresh density test was done in compliance to British Standard (BSI, BS 1881: Part 107). Compressive strength test was done according to relevant British Standard (BS EN 12390-3: 2002) on a $100 \mathrm{~mm}$ concrete cube specimen; compressive strength was determined as the average value taken from 3 specimens as per the relevant standards. However, when the standard deviation was increased to a value which is more than $3 \mathrm{MPa}$, an additional specimen was tested and the average value of the closest 3 specimens was determined.

\section{Results and Discussion}

\subsection{Properties of $R H A$}

The husk was burned at a temperature not exceeding $690{ }^{\circ} \mathrm{C}$. The heating and cooling ramps, burning duration, in addition to the temperature inside the furnace are shown in Figure 3. According to the XRD graph the ash was mainly in amorphous form due to the broad peak on $2 \theta$ angle of $22^{\circ}$. Figure 4 shows the X-ray diffractometer graph, many researchers showed that the minimum temperature for crystallization of the silica in RHA is to be $800{ }^{\circ} \mathrm{C}^{3,5,10}$.

When RHA samples were scanned by electron microscope, the pictures showed the RHA's multilayered, angular and microporous surface, thus explaining its high specific surface area ${ }^{11}$ (Figure 5), the ash was grey in colour and the loss on ignition was relatively high

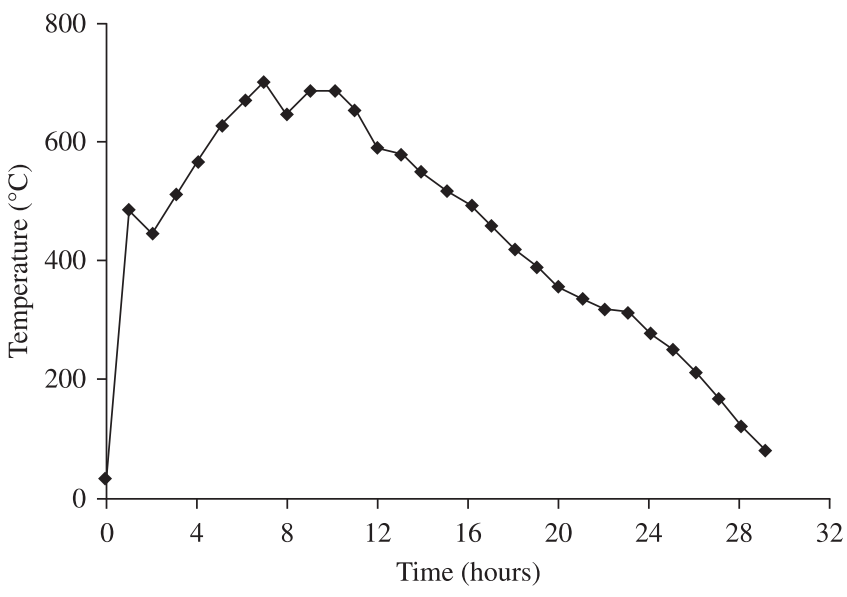

Figure 3. The burning temperature and duration for RHA.

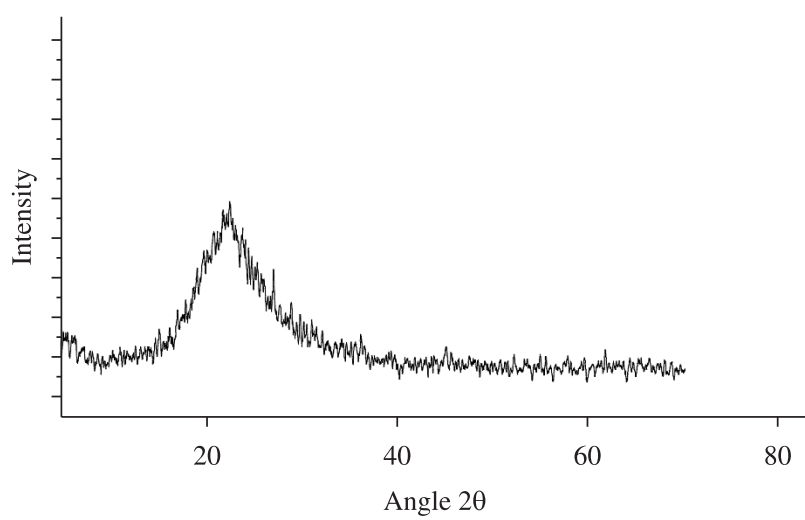

Figure 4. The X-Ray spectrum of RHA.

due to the amount of unburnt carbon in the ash. The chemical and physical properties of RHA are shown in Table 1.

\subsection{The effect of grinding RHA on its APS and specific surface area}

When RHA was ground using the LA machine, the size decreased from 63.8 to $11.5 \mu \mathrm{m}$ for a grinding time of 90 to 360 minutes respectively (Table 2). Figure 6 represents the grinding time against APS. The specific surface area of the ashes are also shown in Figure 6, it can be clearly seen that the surface area only slightly increased by increasing the grinding time, this indicates that the high surface area of RHA is resulted from its microporous and multilayered surface. Thus, the APS has no significant effect on its surface area. The grading curves of RHA and cement are shown in Figure 7. 


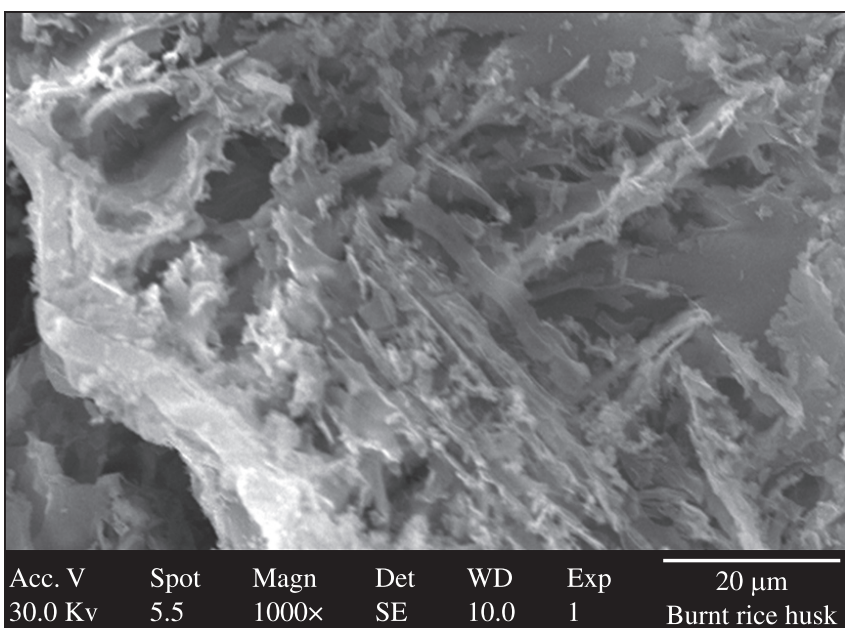

Figure 5. SEM for RHA particle.

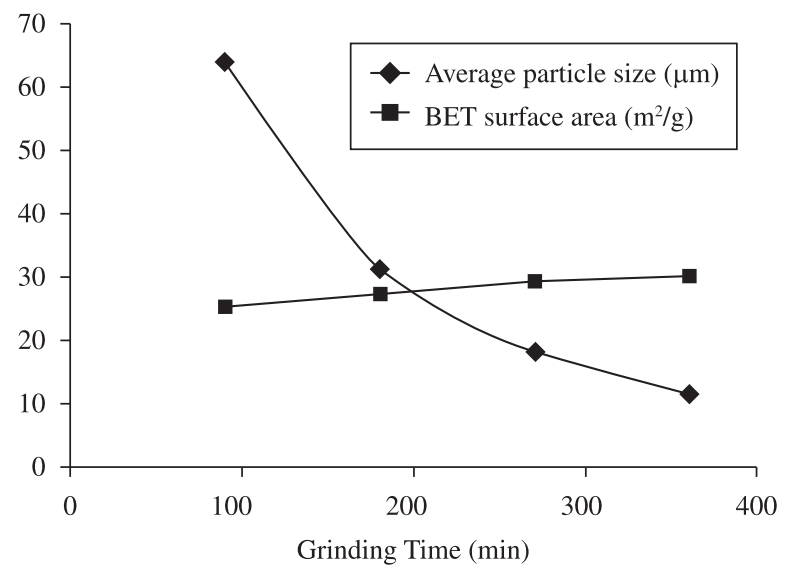

Figure 6. Average particle size and specific surface area of RHA against grinding time.

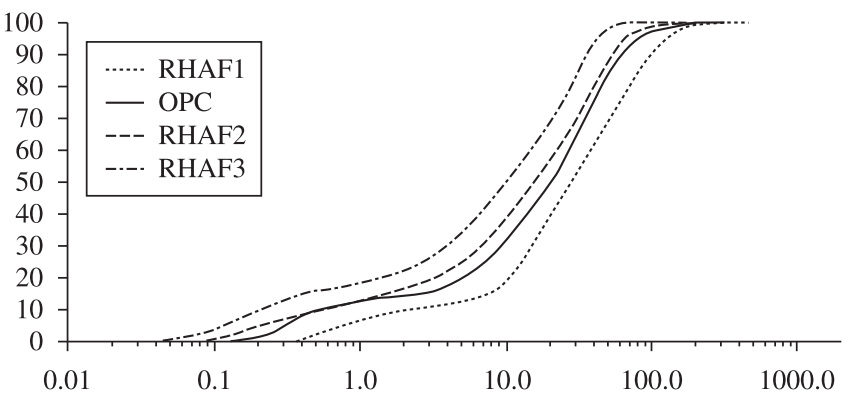

Figure 7. Grading curves of RHA and cement shown by laser particle analyser.

\subsection{The effect of RHA APS and percentage on workability and density of concrete}

The fresh properties of concrete mixtures are given in Table 5; the slump was in the range of $200-240 \mathrm{~mm}$, bleeding was negligible for the control mixture. For concretes incorporating RHA, no bleeding or segregation was recorded. The fresh density was in the range of 2253 to $2351 \mathrm{~kg} . \mathrm{m}^{-3}$, the lowest density values were for $20 \mathrm{~F} 1$ mixture, and this is due to the low specific gravity of RHA which leads to the reduction in the mass per unit volume. The concretes incorporating finer RHA resulted in denser concrete matrix. The SP content had

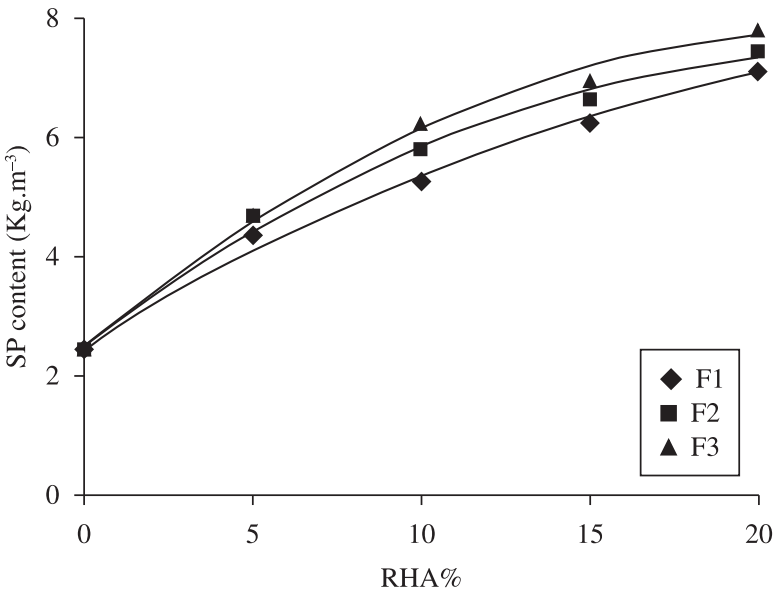

Figure 8. The effect of RHA percentage and APS on the SP content.

Table 5. Fresh concrete properties.

\begin{tabular}{cccccc}
\hline Mix & $\begin{array}{c}\text { RHA } \\
\text { content }(\%)\end{array}$ & $\begin{array}{c}\text { SP content } \\
(\%)\end{array}$ & $\begin{array}{c}\text { Slump } \\
(\mathrm{mm})\end{array}$ & $\begin{array}{c}\text { Fresh density } \\
\left(\mathrm{kg} . \mathrm{m}^{-3}\right)\end{array}$ & Bleeding \\
\hline $\mathrm{CM}$ & 0 & 0.63 & 230 & 2347 & Negligible \\
$05 \mathrm{~F} 1$ & 5 & 1.12 & 200 & 2328 & - \\
$10 \mathrm{~F} 1$ & 10 & 1.35 & 210 & 2293 & - \\
$15 \mathrm{~F} 1$ & 15 & 1.60 & 220 & 2270 & - \\
$20 \mathrm{~F} 1$ & 20 & 1.83 & 220 & 2253 & - \\
$05 \mathrm{~F} 2$ & 5 & 1.20 & 215 & 2335 & Negligible \\
$10 \mathrm{~F} 2$ & 10 & 1.48 & 220 & 2301 & - \\
$15 \mathrm{~F} 2$ & 15 & 1.70 & 220 & 2284 & - \\
$20 \mathrm{~F} 2$ & 20 & 1.90 & 215 & 2270 & - \\
$05 \mathrm{~F} 3$ & 5 & 1.20 & 205 & 2351 & - \\
$10 \mathrm{~F} 3$ & 10 & 1.60 & 230 & 2312 & - \\
$15 \mathrm{~F} 3$ & 15 & 1.78 & 210 & 2305 & - \\
$20 \mathrm{~F} 3$ & 20 & 2.00 & 210 & 2294 & - \\
\hline
\end{tabular}

to be increased along with the RHA fineness and content due to the high specific surface area of RHA which would increase the water demand $^{5,12}$, therefore, to maintain high workability, SP content rose up to $2 \%$ for the $20 \mathrm{~F} 3$ mixture. The superplasticizer (SP) content and RHA percentage for F1, F2 and F3 is shown in Figure 8.

\subsection{The effect of RHA APS on compressive strength of concrete}

The compressive strength development at various ages is given in Table 6. The results showed that at early ages the strength was comparable, while at the age of 28 days, finer RHA concrete exhibited higher strength than the concrete with coarser RHA. For example, at replacement level of $10 \%$, the percentage of increment for RHA concretes compared to the control OPC mix were 22.2, 26.7 and $30.8 \%$ for $10 \mathrm{~F} 1,10 \mathrm{~F} 2$ and $10 \mathrm{~F} 3$, respectively. This is due to the fact that the higher fineness of RHA allowed it to increase the reaction with $\mathrm{Ca}(\mathrm{OH})_{2}$ to produce more calcium silicate hydrate $(\mathrm{C}-\mathrm{S}-\mathrm{H})$ resulting in higher compressive strength, in addition to that, the fine RHA particles contributed to the strength development by acting as a microfiller and enhancing the cement paste pore structure. Similar results were found by Ismail and Walliuddin ${ }^{13}$, that studied the effect of RHA on high strength concrete and found that RHA fineness can enhance the strength. Figure 9 represents the effect of RHA particle size on strength. 
Table 6. Strength development for RHA concrete.

\begin{tabular}{cccccc}
\hline Mixture & RHA & \multicolumn{4}{c}{ Compressive strength (MPa) } \\
\cline { 3 - 6 } & Content $(\%)$ & 1 day & 3 days & 7 days & 28 days \\
\hline CM & 0 & $19.1_{(2.4)}$ & $26.7_{(2.2)}$ & $30.2_{(2.1)}$ & $39.6_{(1.4)}$ \\
$05 F 1$ & 5 & $17.9_{(2.6)}$ & $25.3_{(2.5)}$ & $30.0_{(1.7)}$ & $40.2_{(1.6)}$ \\
$10 F 1$ & 10 & $19.4_{(2.1)}$ & $28.1_{(1.3)}$ & $34.3_{(2.8)}$ & $48.4_{(2.8)}$ \\
$15 F 1$ & 15 & $18.2_{(2.6)}$ & $25.1_{(1.9)}$ & $31.3_{(1.4)}$ & $42.4_{(2.0)}$ \\
$20 F 1$ & 20 & $17.3_{(2.0)}$ & $24.5_{(2.6)}$ & $29.8_{(0.9)}$ & $40.6_{(1.3)}$ \\
$05 F 2$ & 5 & $17.2_{(2.4)}$ & $26_{(2.1)}$ & $29.8_{(2.6)}$ & $40.7_{(2.5)}$ \\
$10 F 2$ & 10 & $20.3_{(2.9)}$ & $28.2_{(2.4)}$ & $35.0_{(1.7)}$ & $50.2_{(2.2)}$ \\
$15 F 2$ & 15 & $18.0_{(2.4)}$ & $25.2_{(1.7)}$ & $30.8_{(2.8)}$ & $42.9_{(1.4)}$ \\
$20 F 2$ & 20 & $17.8_{(2.8)}$ & $24.5_{(2.9)}$ & $30.5_{(2.2)}$ & $41.0_{(2.1)}$ \\
$05 F 3$ & 5 & $18.3_{(3.0)}$ & $25.4_{(2.0)}$ & $31.1_{(1.1)}$ & $42.2_{(1.1)}$ \\
$10 F 3$ & 10 & $19.9_{(2.3)}$ & $29.6_{(2.2)}$ & $36.7_{(2.7)}$ & $51.8_{(1.7)}$ \\
$15 F 3$ & 15 & $19.3_{(1.7)}$ & $26.1_{(2.7)}$ & $32.7_{(1.3)}$ & $44.4_{(2.9)}$ \\
$20 F 3$ & 20 & $18.1_{(2.6)}$ & $25.2_{(2.5)}$ & $32.1_{(2.7)}$ & $41.7_{(0.7)}$ \\
\hline
\end{tabular}

The standard deviation of each value is shown in subscript.

\subsection{The effect of RHA percentage on compressive strength of concrete}

In terms of the replacement level, the 5\% replacement level achieved slightly lower values of compressive strength at early ages for up to 7 days except for the $05 \mathrm{~F} 3$ mixture where the compressive strength was higher due to the increased reactivity and the filler effect of RHA. Based on that, it can be noticed that the amount of RHA present when $5 \%$ replacement used is not adequate to enhance the strength significantly. The available silica from the addition of $5 \%$ RHA reacted with only a small portion of $\mathrm{C}-\mathrm{H}$ released from the hydration process and thus, the $\mathrm{C}-\mathrm{S}-\mathrm{H}$ released from the pozzolanic reaction was relatively limited. However, this was overcome by the age of 28 days where the strength achieved higher values than the control.

The strength increased with RHA for up to $10 \%$ which resulted in achieving the maximum value. For example, $10 \mathrm{~F} 3$ mixture resulted in $30.8 \%$ increment compared to the OPC control mix tested at 28 days age, that is due to the pozzolanic reaction of the available silica from the RHA and the amount of C-H available from the hydration process and also due to the microfiller effect when fine RHA is used.

The strength values when RHA was replaced by $15 \%$ were found to be similar to $5 \%$ replacement except that at the age of 7 days, the strength was higher than the control for all RHA mixtures, in this case, the amount of silica available in the hydrated blended cement matrix is probably too high and the amount of the produced $\mathrm{C}-\mathrm{H}$ is most likely insufficient to react with all the available silica and as a result of that, some amount of silica was left without any chemical reaction.

When $20 \%$ of OPC was replaced for RHA, the strength of concrete achieved equivalent values to the OPC control mixture. Increasing the replacement to a level above $20 \%$ was avoided in this study due to the fact that the increased water demand would lead to SP content higher than the manufacturer recommendations (maximum of $2 \%$ by weight of the cementitious materials) which can give an adverse effect on the produced concrete by acting as a retarder and increasing cost. Furthermore, the strength would decrease to a value that is lower than the control. The decrease in the strength by increasing the RHA replacement level is due to the reduction in the cement amount and as a result of that, the released amount of $\mathrm{C}-\mathrm{H}$ due to the hydration process is not sufficient to react with all the available silica from the addition of RHA and thus, the silica will act as inert material and will not contribute to the strength

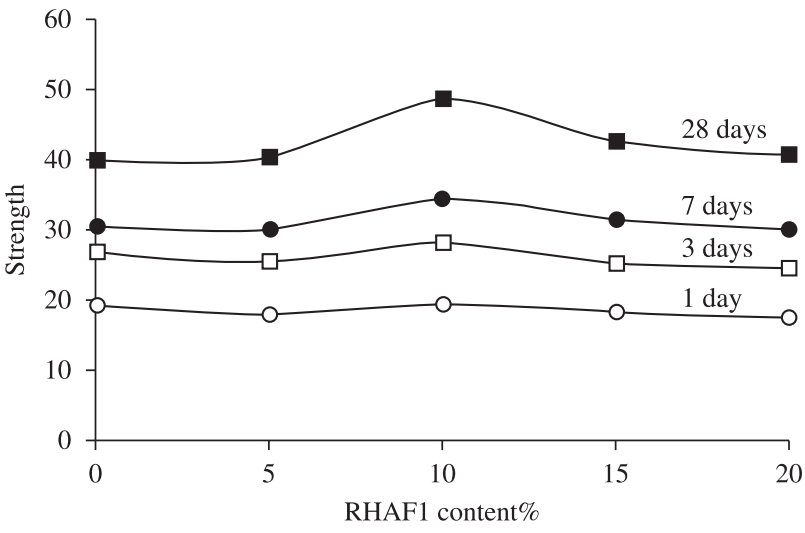

(a)

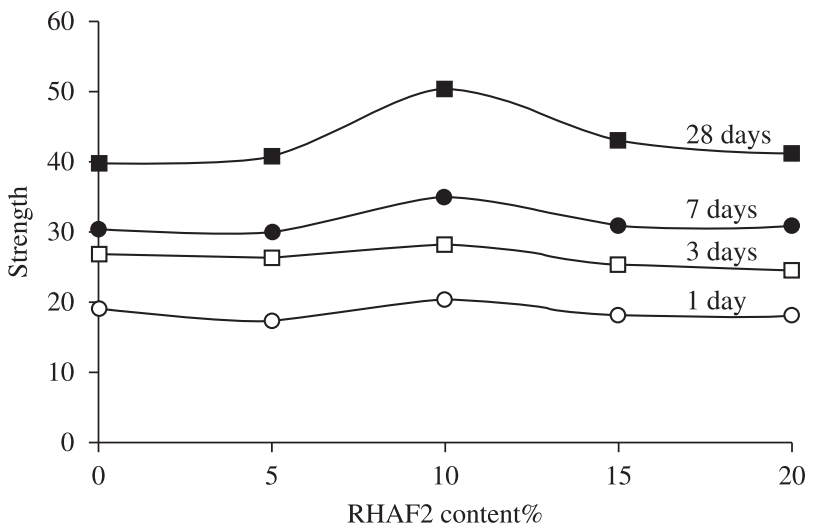

(b)

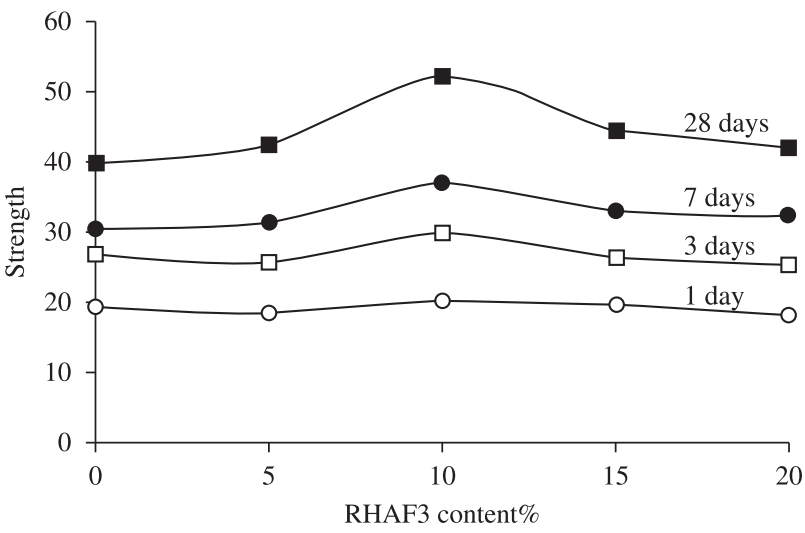

(c)

Figure 9. Relation between strength and RHA level of replacement, a) RHAF1; b) RHAF2; and c) RHAF3.

development except for the fine RHA where it can be considered as a microfiller. The relation between the percentage of RHA replaced and the strength at various ages is shown in Figure 9.

\section{Conclusions}

The RHA used in this study is efficient as a pozzolanic material; it is rich in amorphous silica (88.32\%). The loss on ignition was relatively high $(5.81 \%)$. Increasing RHA fineness increases its reactivity.

Grinding RHA to finer APS has slightly increased its specific surface area, thus, RHA APS is not the main factor controlling its surface area. 
The dosage of superplasticizer had to be increased along with RHA fineness and content to maintain the desired workability.

The compressive strength of the blended concrete with $10 \%$ RHA has been increased significantly, and for up to $20 \%$ replacement could be valuably replaced by cement without adversely affecting the strength. Increasing RHA fineness enhances the strength of blended concrete.

\section{References}

1. Food and Agriculture Organization of the United Nations. World paddy production. 2008. [Accessed 26 December 2008]. Available from: http:// www.fao.org/newsroom/en/news/2008/1000820/index.html.

2. Chandrasekhar S, Satyanarayana K, Pramada P and Majeed J. Effect of calcinations temperature and heating rate on the optical properties and reactivity of rice husk ash. Journal of Materials Science (Norwell), 2006; 41(1):7926-7933.

3. Chandrasekhar S, Satyanarayan KG, Pramada PN and Raghavan P. Review processing, properties and applications of reactive silica from rice husk-an overview. Journal of Materials Science (Norwell), 2003; 38(15):3159 - 3168 .

4. Reddy DV and Marcelina BS. Marine durability characteristics of rice husk ash-modified reinforced concrete. In: International Latin American and Caribbean Conference for Engineering and Technology; 2006 Jun 21-2; Mayaguez, Puerto Rico. Puerto Rico: University of Puerto Rico at Mayagüez; 2006.

5. Zhang MH and Malhotra VM. High-performance concrete incorporating rice husk ash as a supplementary cementing materials. ACI Materials Journal (Detroit), 1996; 93(6):629-636.
6. Nair D, Fraaij A, Klaassen A and Kentgens A. A structural investigation relating to the pozzolanic activity of rice husk ashes. Cement and Concrete Research (Elmsford), 2008; 38(6):861-869.

7. Mehta PK. Rice husk as: a unique supplementary cementing material. In: Proceedings of the International Symposium on Advances in Concrete Technology; 1992 May; Athens, Greece. Canada: CANMET, 1992. p. 407-430.

8. Mahmud HB. Strength property of rice husk ash concrete. In: International Conference on Fly Ash, Silica Fume, Slag and Natural Pozzolans in Concrete; 1995; Milwaukee, USA. Milwaukee: Amer Concrete Inst; 1995. p. 11. (Publication, 153).

9. Neville, AM. Properties of concrete. 4 th. ed. Pearson Education; 2005.

10. Huang S, Jing S, Wang JF, Wang ZW and Jin Y. Silica white obtained from rice husk in a fluidized bed. Powder Technology (Lausanne), 2001; 117:232-238.

11. Zhang MH, Lastra R and Malhotra VM. Rice-husk ash paste and concrete: some aspects of hydration and the microstructure of the interfacial zone between the aggregate and paste. Cement and Concrete Research (Elmsford), 1996; 26(6):963-977.

12. Ganesan K, Rajagopal K and Thangavel K. Rice husk ash blended cement: assessment of optimal level of replacement for strength and permeability properties of concrete. Construction and Building Materials (Guildford), 2008; 22(8):1675-1683.

13. Ismail MS and Waliuddin AM. Effect of rice husk ash on high strength concrete. Construction and Building Materials (Guildford), 1996; 10(7):521-526. 